\title{
Experimental investigation of panel radiator heat output enhancement for efficient thermal use under actual operating conditions
}

\author{
Tamer Calisir ${ }^{1, a}$, Senol Baskaya ${ }^{1}$, Hakan Onur Yazar $^{2}$ and Sinan Yucedag ${ }^{2}$ \\ ${ }^{1}$ Gazi University, Mechanical Engineering Department, 06570 Ankara, Turkey \\ ${ }^{2}$ DemirDokum A.S., R\&D Department, 11300 Bozuyuk, Turkey
}

\begin{abstract}
In this study the heat output of a panel-convector-convector-panel radiator (PCCP) under controlled laboratory conditions under Turkish household and especially Ankara conditions was investigated experimentally. In this sense, investigations were performed for different heating water mass flow rates, water inlet temperatures and radiator inlet and outlet connection positions, which are most commonly used in Turkey. An experimental setup was built for this purpose in a test room where temperature was controlled and held constant during the experiments. Inlet and outlet water temperatures and mass flow rates were measured and heat output of the radiator was calculated. Infrared thermal camera visualizations of the steel panel radiator front surface were also performed.
\end{abstract}

\section{Introduction}

Panel radiators are one of the most widely used heating devices in Europe and Turkey. Within the European Union there is a demand for a reduction in the total energy consumption. Here heating of buildings plays a key role where large amounts of energy is used. Accordingly, there is an increasing demand for more efficient heating systems. So it is important to increase the efficiency of steel panel radiators which usually consist of water channels equipped with convection fins to improve their heat output.

Different types of radiators have been analysed by various researchers. Myhren and Holmberg [1] investigated numerically the radiator heat output and comfort temperatures in a small one-person office using different positions for the ventilation air inlet. Beck et al. [2] considered the enhancement of the heat transfer from panel radiators by the use of either one or two high emissivity sheets placed between the interior surfaces of a double radiator. In the study of Pillutla et al. [3] the head loss coefficient for two common configurations of radiators used in domestic heating systems was identified and compared. In another study of Myhren and Holmberg [4] the performance test results of several ventilation radiator models conducted under controlled laboratory conditions was presented. Aydar and Ekmekci [5] performed CFD analysis of existing panel radiators with a commercial CFD code with variable connection method in three dimensional space. They obtained numerically the thermal efficiency values and compared these with given catalogue values. The variation in the heat output of panel radiators obtained by altering the emissivity of the wall behind them has been examined by Beck et al.
[6]. Their work was conducted through experiments and CFD.

Erdogmus [7] conducted experimental studies in a standard test room to determine heat outputs of radiators. The heat dissipation capabilities of three different panel radiators were also determined using numerical methods.

There are several ways to make heat emitters more thermally efficient. Myhren and Holmberg [8] varied the distribution of vertical longitudinal convection fins to optimize the heat output of ventilation radiators. In another study Myhren and Holmberg [9] focused on how different heating systems and their position affect the indoor climate in an exhaust-ventilated office under Swedish winter conditions. Eijdems et al. [10] showed that by lowering the temperatures for heat distribution systems, advantages on indoor air quality, thermal comfort and energy consumption were found. Peukert and Müller [11] described measurements based on mass flow and temperature of floor convectors in cooling and heating regimes. Thermographic investigation of a heating panel radiator under various conditions, especially with various heating water volume flow rates was described by Jancik and Basta [12]. Müller et al. [13] presented the measurement results of the influence of wall temperature on flow from a floor convector. Measurements were realized in an open space laboratory.

The aim of this study is to experimentally investigate the heat output of a panel-convector-convector-panel radiator (PCCP) under controlled laboratory conditions, in agreement with Turkish household conditions, and especially applicable to Ankara preferences. In this sense, investigations were performed for different heating water mass flow rates, water inlet temperatures and connection positions, which are most commonly used in Turkey. The

\footnotetext{
${ }^{a}$ Corresponding author: tamercalisir@gazi.edu.tr
} 
results obtained in this study will guide in the enhancement of thermal efficiency of panel radiators. An experimental setup was built for this purpose and tests were performed. In the study, inlet and outlet water temperatures and mass flow rates were measured, and IR visualizations of the steel panel radiator surface temperature were performed. The test room temperature was controlled and held constant during the performance tests.

\section{Experimental setup}

In this part of the study the experimental setup is described. The experimental setup is shown in Figure 1. Experiments were performed in a climatic test room where temperature conditions can be stable and the temperature of $25^{\circ} \mathrm{C}$ was used as the temperature of the test room. This temperature was selected due to the common temperature conditions in Turkish households which are in general higher than EN 442-2 standard [14]. The radiator performance test rig consists of a $1000 \mathrm{~mm}$ $\times 600 \mathrm{~mm}$ radiator, circulating constant temperature water bath, two immersion type thermocouples to measure water temperatures at the inlet and outlet of the radiator, a rotameter, a computer connected data logger for tracking the temperatures of the room and radiator inlet and outlet ports, and necessary piping. In addition an infrared thermal imaging system was used to obtain the surface temperature of the radiator.

As can be seen from Figure 1, the heating water was heated in a circulating constant temperature water bath to the desired temperature, and was sent through the piping to the radiator. The flow rate was measured using a rotameter and the desired flow rate was adjusted using a by-pass connection. The rotameter was mounted at the outlet side of the radiator. At the inlet and outlet ports of the radiator self-made immersion thermocouples were used, and temperature outputs were sampled using a datalogger, which was connected to a computer with analysing software. A check valve was used to barrier the water flow in the down flow side. A DemirDöküm Panel Plus radiator was used in the performance tests. The distance between the nearest heat emitting surface of the radiator and the outer wall is $0.05 \mathrm{~m}$. Tested radiator is positioned at a height of $0.11 \mathrm{~m}$ above the floor according to EN 442-2 [14].

During the temperature measurements a total of six Ttype thermocouples were used. Two of them were used to measure the inlet and outlet temperatures of the radiator heating water. Four thermocouples were used to track the room temperature. These were placed according to EN 442-2 [14] at the center of the climatic room at vertical heights of $0.05 \mathrm{~m}, 0.75 \mathrm{~m}$, and $1.50 \mathrm{~m}$ from the bottom, and $0.05 \mathrm{~m}$ from the ceiling. The test room has dimensions of $5 \mathrm{~m} \times 4 \mathrm{~m} \times 2.55 \mathrm{~m}$.

Temperature values were obtained with the HIOKI LR8431-20 data logger. The circulating water bath used in the study was LabCompanion $2025 \mathrm{G}$ and was operated in the temperature range of $40-80{ }^{\circ} \mathrm{C}$.

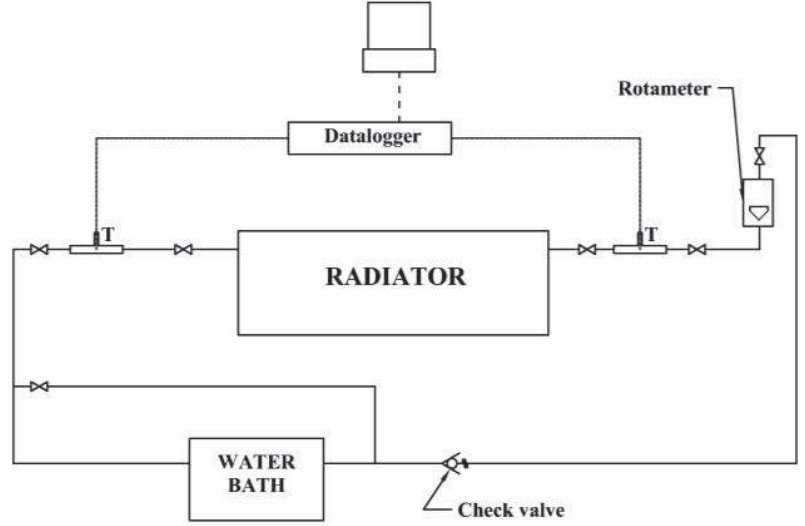

Figure 1. Experimental setup.

Measurements were performed for water inlet temperatures which were adjusted on the circulating water bath in the range of $40-80{ }^{\circ} \mathrm{C}$, and flow rates of $0.01-0.022 \mathrm{~kg} \mathrm{~s}^{-1}$. Different arrangements of inlet and outlet positions of top-bottom-same-end connection (TBSE), top-bottom-opposite-end (TBOE) and bottombottom-opposite-end (BBOE) were also considered in the experimental study. All these parameters were selected considering the household conditions in Turkey and especially in Ankara.

The heat output is calculated from temperature data collected in steady state test room conditions and inletoutlet temperature values. Therefore the main consideration in the measurements is that whether or not all the temperatures reach the steady state condition. The steady state condition was followed with controlling the temperature values. After the steady state conditions were obtained, measurements were started, and all tests were continued for a minimum of 30 minutes according to EN 442-2 [14].

\subsection{Data reduction}

The equations used to obtain the heat output of the radiator are presented in this section.

The heat output of the radiator was calculated using Eq. (1).

$$
Q=m c_{p}\left(T_{\text {in }}-T_{\text {out }}\right)
$$

where $Q$ shows the heat output, W, $m$ the mass flow rate, $\mathrm{kg} \mathrm{s}^{-1}, c_{p}$ specific heat of water, $\mathrm{J} \mathrm{kg}^{-1} \mathrm{~K}^{-1}$, and $T_{\text {in }}$ and $T_{\text {out }}$ the water inlet and outlet temperatures, ${ }^{\circ} \mathrm{C}$, respectively.

Properties of water were obtained at the arithmetic mean temperature using thermodynamic tables. The arithmetic mean temperature was calculated as follows;

$$
T_{m}=\left(T_{\text {in }}+T_{\text {out }}\right) / 2
$$

where $T_{m}$ shows the arithmetic mean temperature, ${ }^{\circ} \mathrm{C}$.

Although the volume flow rate was measured the mass flow rate was calculated using Eq. (3).

$$
m=\rho V
$$


$V$ and $\rho$ are the volume flow rate, $\mathrm{m}^{3} \mathrm{~s}^{-1}$, and density of water at the arithmetic mean temperature, $\mathrm{kg} \mathrm{m}^{-3}$, respectively.

\section{Results and discussion}

The results obtained from the experimental study are shown in this part. Investigations were performed for water bath temperatures of $40-80^{\circ} \mathrm{C}, 0.01-0.022 \mathrm{~kg} \mathrm{~s}^{-1}$. Different arrangements of inlet and outlet positions of top-bottom-same-end connection (TBSE), top-bottomopposite-end (TBOE) and bottom-bottom-opposite-end (BBOE) were also considered in the experimental study. All these parameters were selected considering the household conditions in Turkey and especially in Ankara. Also IR camera visualizations were performed and relevant results were presented as temperature contours.

\subsection{Effect of radiator inlet temperature}

The effect of radiator inlet temperature on the heat output of the radiator was investigated for different inlet-outlet connection positions.

The effect of inlet temperature on the heat output for different mass flow rates is presented in Figure 2 - Figure 4 for TBSE, TBOE and BBOE, respectively. As can be seen from the figures the heat output is almost linearly increasing with increasing inlet temperature. It was observed that in general the heat output at low temperatures, except TBOE arrangement, is very close and almost the same for all mass flow rates. Although there are some exceptions it can be said that in general the higher the mass flow rate a larger higher heat output is obtained.

In Figure 2 the effect of inlet temperature on heat output is presented for TBSE at different mass flow rates. As mentioned before the heat output is almost the same for all flow rates at low inlet temperatures, but the highest heat output values are observed for $\mathrm{m}=0.022 \mathrm{~kg} \mathrm{~s}^{-1}$ at almost all temperatures except of the highest inlet temperature, where the highest output is obtained for $\mathrm{m}=$ $0.014 \mathrm{~kg} \mathrm{~s}^{-1}$. This is attributed to the fact that at higher temperatures a better temperature difference is obtained for $\mathrm{m}=0.014 \mathrm{~kg} \mathrm{~s}^{-1}$.

For the TBOE arrangement the effect of inlet temperature is shown in Figure 3. It is observed that the mass flow rate has almost no effect on the heat output except at the lowest inlet temperature, where almost 53\% difference in heat output is obtained.

The effect of inlet temperature for BBOE arrangement is presented in Figure 4. It was observed that the mass flow rate has almost no effect on heat output at different inlet temperatures.

In this section the effect of inlet temperature on the heat output for different mass flow rates and inlet-outlet connection positions was shown. It can be concluded that the heat output is almost linearly increasing with increasing inlet temperature for all connection positions. Mass flow rates have almost no effect for TBOE and BBOE connections. This is not the case for TBSE where higher differences occurred for different mass flow rates.

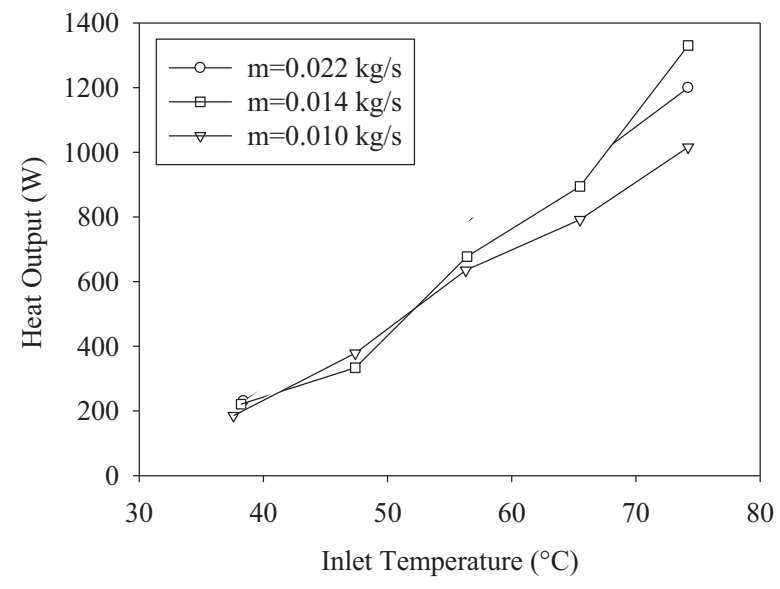

Figure 2. Effect of inlet temperature for TBSE arrangement.

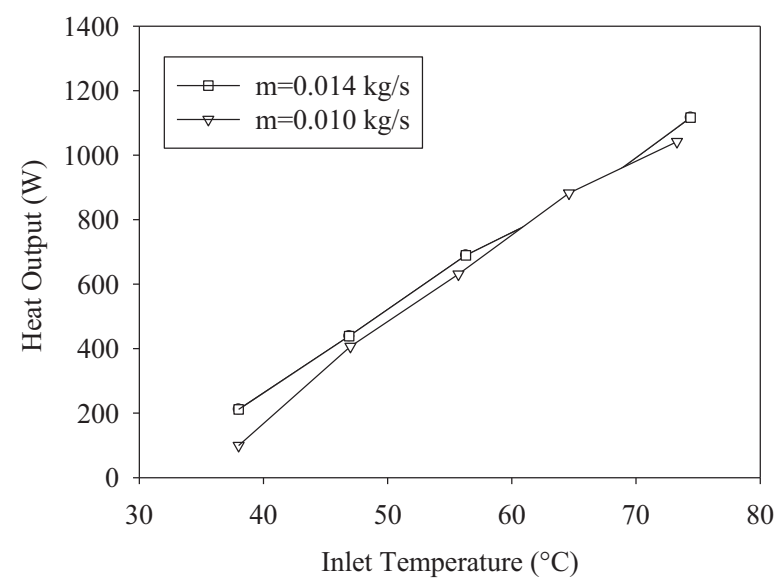

Figure 3. Effect of inlet temperature for TBOE arrangement.

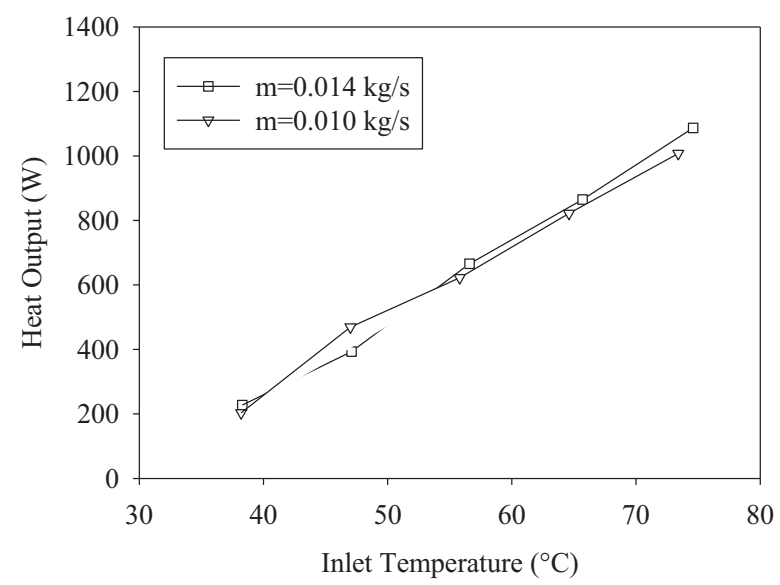

Figure 4. Effect of inlet temperature for BBOE arrangement.

\subsection{Effect of temperature difference}

The effect of temperature difference $(\Delta T)$ between the inlet and outlet of the radiator on the heat output of the radiator was investigated for different inlet-outlet connection positions.

The effect of $\Delta \mathrm{T}$ for the TBSE, TBOE and BBOE connection positions is shown in Figure 5 - Figure 7, respectively. As expected, the heat output is increasing almost linearly with increasing temperature difference. It is observed that with increasing mass flow rate lower 
temperature differences occur. This shows that the heating water cannot transfer its heat through the water channels and convectors to the surrounding air. Although the temperature difference is in general lower with increasing flow rate, higher heat output values are observed. This is due to the higher flow rate which is an important parameter as can be seen in Eq. 1. Due to these observations it can be seen that with increasing mass flow rate the heat output increases with a higher slope. The increase in the temperature difference is higher for lower mass flow rates.

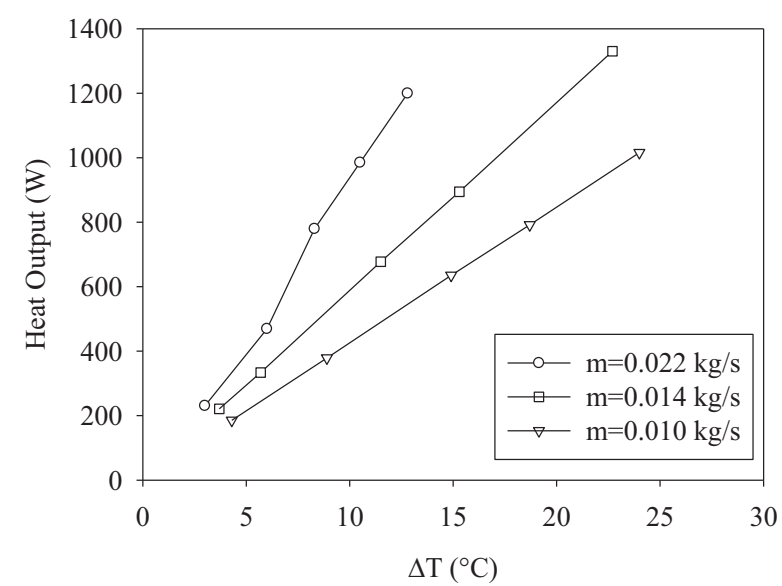

Figure 5. Effect of $\Delta \mathrm{T}$ for TBSE arrangement.

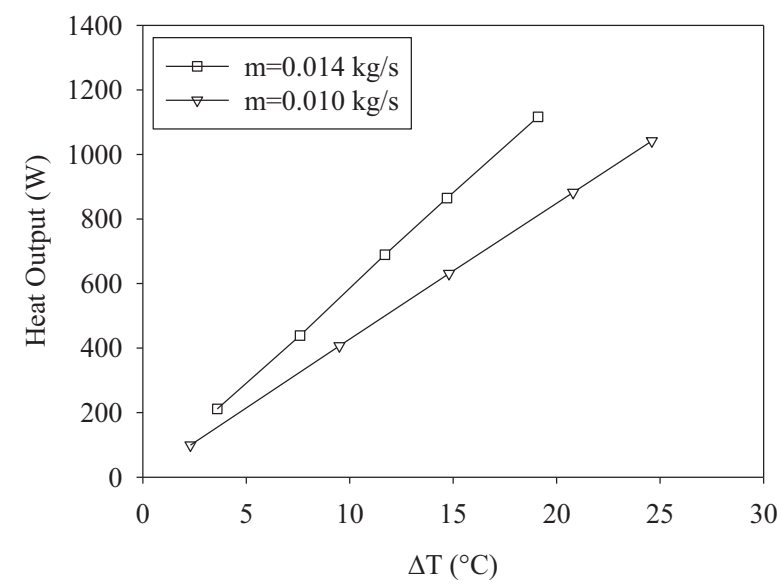

Figure 6. Effect of $\Delta \mathrm{T}$ for TBOE arrangement.

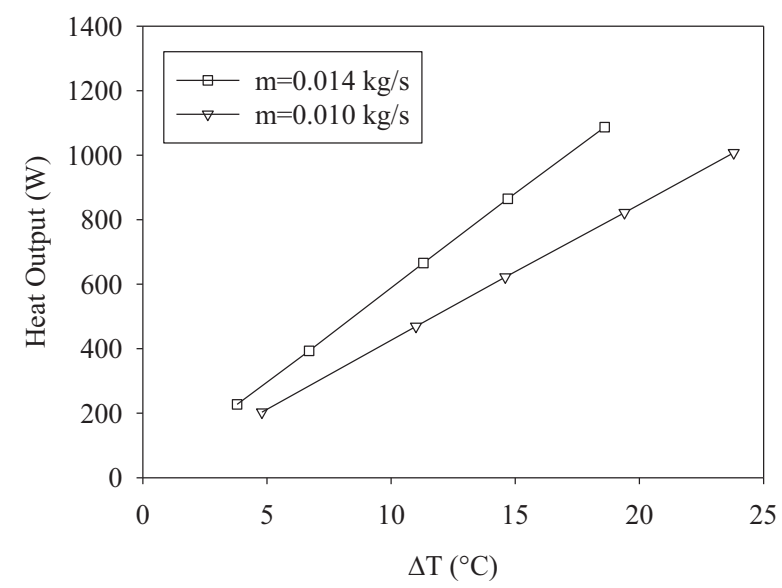

Figure 7. Effect of $\Delta \mathrm{T}$ for BBOE arrangement.
A characteristic equation of the radiator was derived for the three different connection positions. The equations for the TBSE, TBOE and BBOE are presented in Eq. (4) - (6), respectively. It can be seen that the change in mass flow rate changes the slope of characteristic equations. One can also see that the characteristic equations, which were derived as a function of temperature difference and mass flow rate, are affected by the connection position.

$$
\begin{aligned}
& Q=4064.88 \Delta T^{1.033} m^{1.014} \\
& Q=3455.96 \Delta T^{0.997} m^{0.955} \\
& Q=3375.19 \Delta T^{0.991} m^{0.945}
\end{aligned}
$$

Increase in the temperature difference has a significant effect on heat output in the investigated range of mass flow rates. The heating system could also operate at lower mass flow rates which in turn has a positive effect on the circulation pump that will use less energy.

\subsection{Effect of mass flow rate}

The effects of mass flow rate on heat output for TBSE, TBOE and BBOE connection positions is shown in Figure 8 - Figure 10, respectively.

It is observed from the figures that increase in the mass flow rate has in general little effect on heat transfer. Also from the characteristic equations it can be seen that the power of mass flow rate are around unity, and the highest power is obtained for the TBSE connection position. The power for the TBOE and BBOE connection positions are below unity. This can also be observed from the presented results, where it can be seen that the increase in the heat output values are very small.

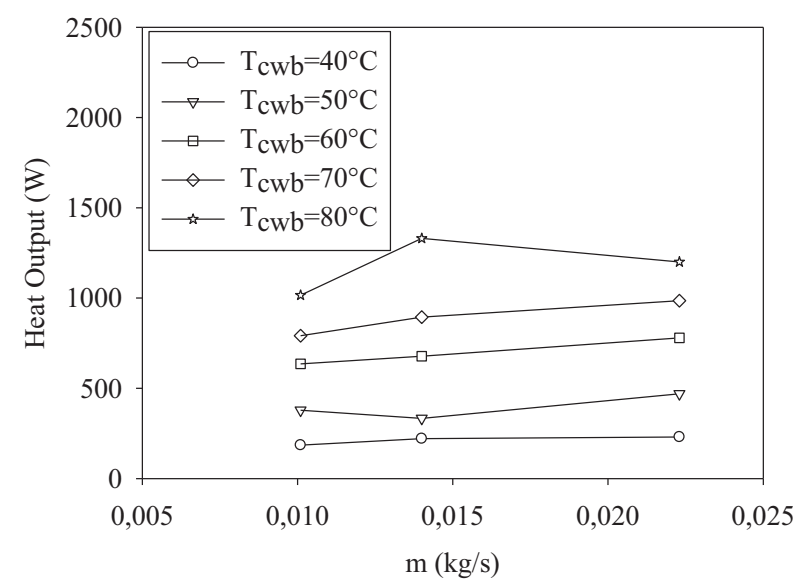

Figure 8. Effect of mass flow rate for TBSE arrangement. 


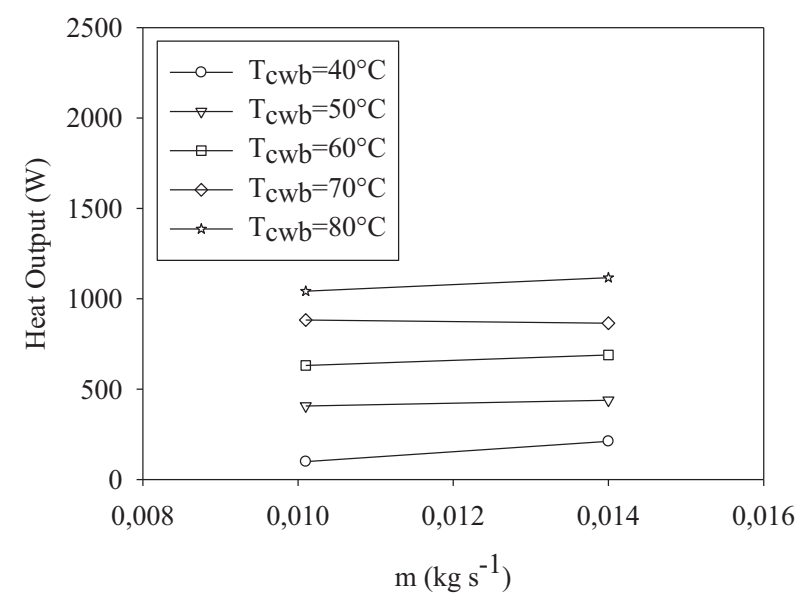

Figure 9. Effect of mass flow rate for TBOE arrangement.

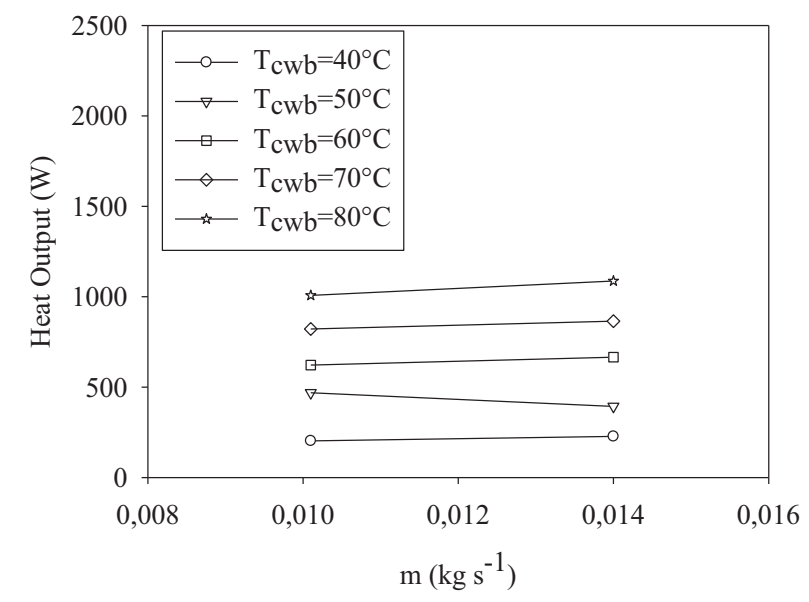

Figure 10. Effect of mass flow rate for BBOE arrangement.

\subsection{Effect of inlet-outlet connection positions}

The effect of inlet and outlet connection position for the investigated positions is shown in Figure 11 for $\mathrm{m}=$ $0.01 \mathrm{~kg} \mathrm{~s}^{-1}$ mass flow rate. It can be seen that for bath temperature of $40{ }^{\circ} \mathrm{C}$ the lowest heat output is observed for TBOE. However this connection position has the highest heat output at $\mathrm{T}_{\mathrm{cwb}}=70^{\circ} \mathrm{C}$ and $80{ }^{\circ} \mathrm{C}$. The TBSE and $\mathrm{BBOE}$ connections have in general close heat output values for all bath temperatures except for $\mathrm{T}_{\text {cwb }}=50^{\circ} \mathrm{C}$.

Similarly, for the mass flow rate of $0.014 \mathrm{~kg} \mathrm{~s}^{-1}$ the effect of inlet and outlet connection on heat output is shown in Figure 12. It can be seen that for this mass flow rate the heat output characteristics are very different compared to Figure 11. It is observed that at $\mathrm{T}_{\mathrm{cwb}}=40{ }^{\circ} \mathrm{C}$ the heat output values for all connection positions are almost the same. For $\mathrm{T}_{\mathrm{cwb}}=50^{\circ} \mathrm{C}$ the highest heat output was observed for TBOE. A higher temperature difference between the inlet and outlet sections is the reason for this value. On the other hand for $\mathrm{T}_{\mathrm{cwb}}=80{ }^{\circ} \mathrm{C}$ the TBSE connection has a significantly higher heat output value which is due to the temperature difference between the inlet and outlet sections of the radiator.

However, there is no clear best connection position observed from Figs. 11-12. It was observed from the characteristic equations that the most effective connection position is obtained for the TBSE position, which is actually the required connection position according to EN 442-2 [14]. It was seen that the highest slope is obtained for the TBSE position, and also the power of temperature difference and mass flow rate are higher in comparison with the other two connection positions.

Temperature distributions on the radiator front panel are shown in Figure 13. The IR thermal camera visualizations were obtained for $\mathrm{T}_{\mathrm{cwb}}=40{ }^{\circ} \mathrm{C}$ and $\mathrm{m}=$ $0.01 \mathrm{~kg} \mathrm{~s}^{-1}$ for the investigated connection positions. The temperature distribution was not uniform for all investigated positions.

The effect of inlet-outlet connection position on the heat output of the radiator was investigated in this section. IR thermal camera visualizations were also obtained and shown. It could be said that in the investigated mass flow range there was no particular preferred connection type observed. For different connection types and water bath temperatures different maximum heat output values are obtained. However, in general the heat output values are very close at $\mathrm{T}_{\mathrm{cwb}}=60$ ${ }^{\circ} \mathrm{C}$ for both mass flow rates.

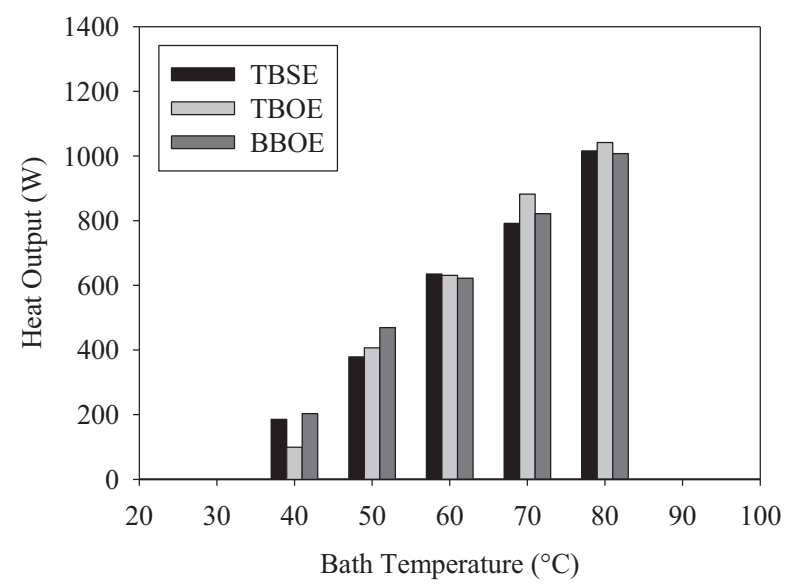

Figure 11. Effect of inlet-outlet position for $\mathrm{m}=0.01 \mathrm{~kg} \mathrm{~s}^{-1}$

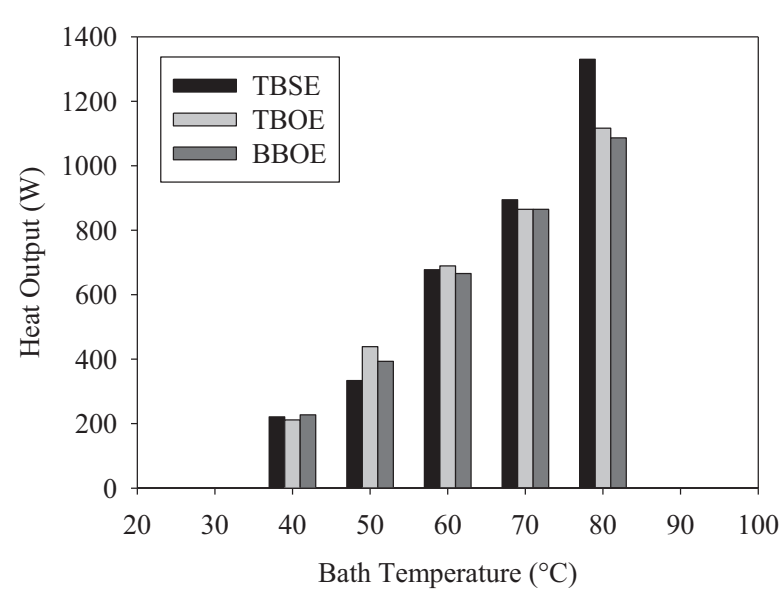

Figure 12. Effect of inlet-outlet position for $\mathrm{m}=0.014 \mathrm{~kg} \mathrm{~s}^{-1}$ 


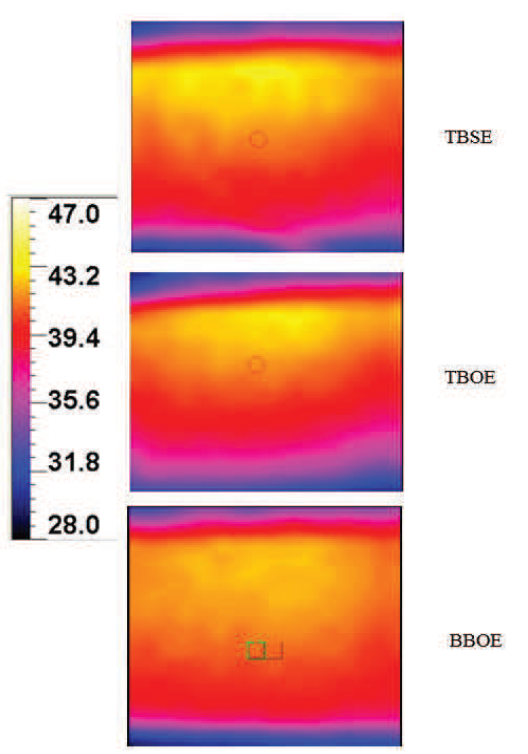

Figure 13. Temperature distribution on the radiator

\section{Conclusion}

The aim of this study was to experimentally investigate the heat output of a panel-convector-convector-panel radiator (PCCP) under controlled laboratory conditions under Turkish household features and especially for Ankara conditions. In this sense, investigations were performed for different heating water mass flow rates, water inlet temperatures and connection positions which are most commonly used in Turkey. The results obtained in this study will guide in the enhancement of thermal efficiency of panel radiator usage.

The effect of inlet temperature on the heat output for different mass flow rates and inlet-outlet connection positions was investigated and it was observed that the heat output is almost linearly increasing with increasing inlet temperature for all connection positions.

The temperature difference between the inlet and outlet of the radiator on the heat output for different mass flow rates and inlet-outlet connection positions was investigated. It was observed that for lower mass flow rates higher temperature differences could be obtained. Although due to the higher mass flow rates higher heat output are observed in general. Increase in the temperature difference has a more significant effect on heat output in the investigated range of mass flow rates, because the increase in temperature difference shows almost the same heat output values.

The effect of inlet-outlet connection position on the heat output of the radiator was investigated and IR thermal camera visualizations were obtained. There is no clear best connection position observed from the graphical presentations. However, from the characteristic equations the most effective connection position is obtained for the TBSE position, which is actually the required connection position according to EN 442-2 [14]. It was seen from the derived equations that the highest slope is obtained for the TBSE position. In addition, the power of temperature difference and mass flow rate are also higher in comparison with the other two connection positions.

According to manufacturers technical data sheet the heat output of the investigated panel radiator is $1798 \mathrm{~W}$. This heat output can be obtained at the following conditions: room temperature $20{ }^{\circ} \mathrm{C}$, TBSE connection and $0.04 \mathrm{~kg} \mathrm{~s}^{-1}$ of mass flow rate. Hence, one can see that user's habits have a very negative effect on the performance of panel radiators.

\section{Acknowledgements}

Financial support of this study by the Ministry of Science, Industry and Technology of Turkey under Grant No. 0641.STZ.2014 and also DemirDöküm A.Ş. are gratefully acknowledged.

\section{References}

1. J.A. Myhren, S. Holmberg, Energy and Buildings 41, 92-100 (2009)

2. S.M.B. Beck, S.C. Grinsted, S.G. Blakey, K. Worden, App. Thermal Engineering 24, 1291-1300 (2004)

3. G. Pillutla, R. Mishra, S.M. Barrans, J. Barrans, Int. Conf. on Renewable Energies and Power QualityICREPQ10, (2010)

4. J.A. Myhren, S. Holmberg, App. Thermal Engineering 51, 315-324 (2013)

5. E. Aydar, I. Ekmekci, J. of Thermal Science and Technology 32 (2), 63-71 (2012)

6. S.B.M. Beck, S.G. Blakey, M.C. Chung, Building Serv. Eng. Res. Technol. 22 (3), 185-194 (2001)

7. A.B. Erdogmus, Simulation of the Heater Test Room Defined by EN 442 Standard and Virtual Testing of different type of Heaters, Ph.D. Thesis, (2011)

8. J.A. Myhren, S. Holmberg, Int. J. of Thermal Sciences 50, 115-123 (2011)

9. J.A. Myhren, S. Holmberg, Energy and Buildings 40, 524-536 (2008)

10. H.H.E.W. Eijdems, A.C. Boerstra, P.J.M. Op't Veld, $20^{\text {th }}$ AIVC and Indoor Air 99 Conference, (1999)

11. P. Peukert, M. Müller, EPJ Web of Conferences 25, 01071 (2012)

12. L. Jancik, J. Basta, EPJ Web of Conferences 25, 01031 (2012)

13. M. Muller, K. Frana, M. Kotek, P. Dancova, EPJ Web of Conferences 45, 01130 (2013)

14. EN 442-2:1996 Radiators and Convectors - Part 2: Test Methods and Rating 